\title{
Prevalence and Associated Factors of Depression and Anxiety Among Patients with Pulmonary Tuberculosis Attending Treatment at Public Health Facilities in Southwest Ethiopia
}

This article was published in the following Dove Press journal:

Neuropsychiatric Disease and Treatment

Mustefa Mohammedhussein (D) ${ }^{1}$

Arefayne Alenko $\mathbb{D}^{2}$

Worknesh Tessema ${ }^{2}$

Almaz Mamaru²

'Department of Psychiatry, Faculty of Public Health and Medical Science, Mettu University, Mettu, Ethiopia; ${ }^{2}$ Department of Psychiatry, Faculty of Medical Science, Institute of Health, Jimma University, Jimma, Ethiopia

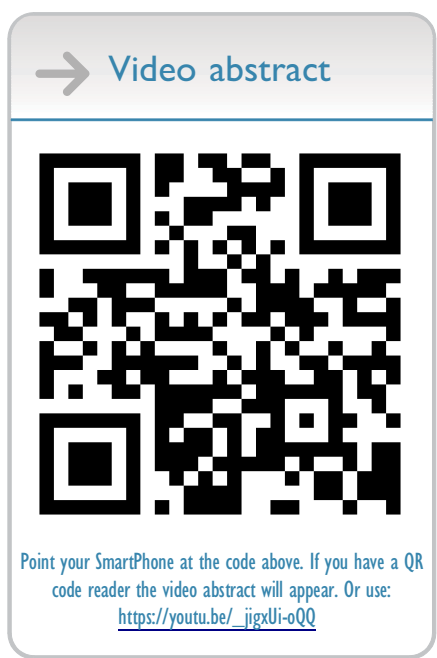

Correspondence: Mustefa

Mohammedhussein

Tel +25I 9235I2698

Email mustefamohammed1984@gmail.com
Background: Depression and anxiety are the most commonly occurring psychiatric comorbidities among patients with pulmonary tuberculosis (PTB). Co-occurring anxiety and depression in PTB patients result in poor adherence to anti-tuberculosis medication. This in turn results in lower success rate of treatment and an upsurge in morbidity and mortality. Despite this problem existing globally, little has been explored in southwest Ethiopia.

Objective: The aim of this study was to assess the prevalence and associated factors of depression and anxiety among patients with pulmonary tuberculosis receiving treatment at public health facilities in southwest Ethiopia.

Materials and Methods: A facility-based cross-sectional study was conducted from April to May 2019. Data were collected from 410 PTB patients using hospital anxiety and depression scale (HADS). Epi data version 3.1 and SPSS version 23 were used to enter and analyze data respectively. Multiple logistic regressions were fitted to identify the strength of association between outcome and explanatory variables. $\mathrm{P}<0.05$ was considered statistically significant.

Results: Prevalence of depression and anxiety among PTB patients were 229 (55.9 \%) and $224(54.6 \%)$, respectively. High perceived stress [AOR=3.61 $(1.99,6.53)]$, perceived stigma $[\mathrm{AOR}=10.13(5.52,18.63)]$, being in an intensive phase of treatment $[\mathrm{AOR}=3.33(1.83$, $6.07)]$, and low body mass index $[\mathrm{AOR}=2.07(1.13,3.80)]$ were significantly associated with depression. Being female $[\mathrm{AOR}=2.42(1.39,4.22)]$, perceived stigma [AOR=3.58 (1.99, $6.42)]$, high perceived stress $[\mathrm{AOR}=4.40(2.52,7.69)]$, and family history of mental illness $[\mathrm{AOR}=2.66(1.19,5.94)]$ had significant association with anxiety.

Conclusion: More than half of the study participants were found to have probable depression and anxiety. This indicates the need to pay attention to the mental health condition of patients with PTB, particularly to those with identified risk factors.

Keywords: anxiety, depression, tuberculosis, Ethiopia

\section{Introduction}

Depression and anxiety are the two main diagnostic classes of common mental disorders which remain a global public health concern. Depression affects more than 300 million people worldwide. ${ }^{1}$ Anxiety was ranked as the sixth largest contributor to non-fatal health loss and globally affects an estimated 264 million people. ${ }^{1}$ 
Tuberculosis (TB) also remains a major global health problem despite the fact that it can be cured with timely diagnosis and appropriate intervention. Worldwide, TB is one of the top ten causes of death, and over $95 \%$ of the cases and deaths occur in developing countries. ${ }^{2}$ Ethiopia is one of the 30 high TB burden countries that collectively accounted for about $87 \%$ of the world's TB cases, and was found in the list of 14 countries that shared the three lists of high TB burden (TB, TB/HIV coinfection and multi-drug resistant TB (MDR-TB)). ${ }^{2}$

Recently, research revealed that concern regarding psychiatric comorbidity, particularly depression and anxiety among TB patients and understanding its significance, has been increasing. The occurrence of depression and anxiety among TB patients is associated with non-compliance to treatment which is considered the main barrier to control TB. Treatment noncompliance in turn escalates the risk of morbidity and mortality from the disease. ${ }^{3-6}$ Anxiety and depression adversely affect the ability to cope with stress, the side effects of medication, and other challenges of daily life in patients with PTB. ${ }^{5,7,8}$

Mainly, depression adversely influences an individual's health care seeking behavior, diet, medication adherence and compliance with treatment causing a considerable challenge for global TB control. ${ }^{9}$ Furthermore, anxiety and depression may exacerbate other primary social susceptibilities imposed by TB related stigma like isolation from social activities and give rise to added long-term impairment of the patient's overall psychosocial well-being. ${ }^{7,8,10-12}$

So far, studies across the world have shown a high prevalence of depression and anxiety among TB patients. ${ }^{3-6,8,13,14}$ In Ethiopia, both were found higher among TB patients; anxiety $41.5 \%{ }^{13}$ and depression in the range of $19.8 \%$ to $54 \%{ }^{11,13,15-17}$ However most of the previous studies have addressed common mental disorders which suggested only psychological distress rather than particular psychiatric disorders. ${ }^{18,19}$ To the best of our knowledge of the available information, the studies that have investigated depression among TB patients and anxiety among TB patients in Ethiopia were very limited. Those studies did not address PTB in particular, thus the current study in particular focused on contributing to the scarce evidence on the prevalence and correlates of anxiety and depression among PTB patients.

\section{Materials and Methods}

\section{Study Design and Setting}

An institution-based cross-sectional study was conducted at public health facilities in Jimma zone from April to
May 2019. The zone has its capital located $352 \mathrm{~km}$ in the southwestern direction from Addis Ababa, the capital city of Ethiopia. In Jimma zone, 124 health centers and 7 hospitals (6 primary and 1 tertiary) are providing services. During the study period around 617 PTB patients had follow-up appointments in public health facilities of the zone.

\section{Source and Study Population}

Pulmonary tuberculosis patients who were being followedup at public health facilities of Jimma zone were the source population, whereas patients with PTB aged $\geq 18$ who were being followed-up in selected health facilities during the study period were the study population. Critically ill patients (those unable to respond because of the illness) and those on treatment for less than a month were excluded.

\section{Sample Size Determination}

The sample size required for the study was determined by using single population proportion formula by considering $95 \%$ of confidence level that falls within $5 \%$ margin of error, $10 \%$ non-response rate and $\mathrm{P}=(41.5 \%$ prevalence of anxiety among tuberculosis patient, $43.4 \%$ prevalence of depression among tuberculosis: from study conducted in Walaita Sodo, Ethiopia). ${ }^{13}$ After sample size was calculated for the two outcome variables (depression and anxiety), larger value was taken $(n=414)$.

\section{Sampling Procedures}

Thirty nine (39) health facilities were selected randomly (by lottery method) from 131 public health facilities in Jimma zone. All eligible PTB patients who visited the selected health facilities during the study period (AprilMay, 2019) were consecutively included. Of the total 447 PTB patients who visited the selected health facilities, 414 $(n=414)$ were found eligible for the study, $4(0.97 \%)$ of them refused to participate in the study. To avoid double counting, patients who attended more than once during the study period were included only on the first contact. The detail sampling procedure is shown in Figure 1.

\section{Data Collection Method and Instrument}

Data were collected by trained nurses through face-to-face interview at health facilities using translated and pretested questionnaire. The data collection instrument had the following components. Socio-demographic factors were assessed by structured questionnaire. Oslo 3 items perceived social support scale was used to assess perceived 
Jimma Zone

131 Public health Facilities (124 Health Centers \& 7 Hospitals)

39 Health facilities are randomly selected by lottery method

(37 Health Centers and 2 Hospitals)

All eligible PTB patients who visited the selected health facilities during the

study period who agreed to participate were consecutively included

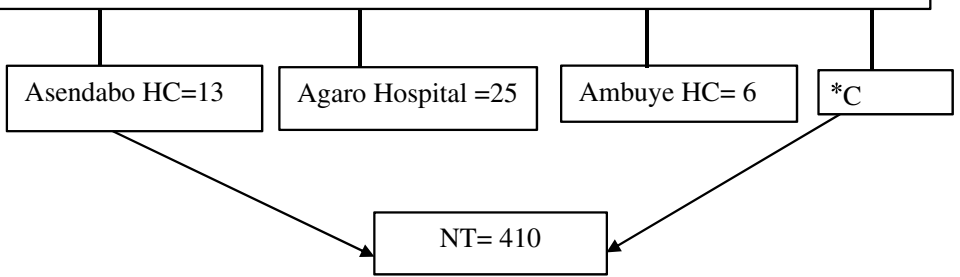

Figure I Flow chart of sampling procedure to select patients with PTB at public health facilities in southwest Ethiopia, 20I9 ( $=410$ )

Notes: " $\mathrm{C}=$ continue subsequently: Agaro HC ( $n=14)$, Bilida HC ( $n=9)$, Baballa HC $(n=5)$, Bake gudo HC $(n=9)$, Babo HC ( $n=7)$, Beshasha HC ( $n=7)$, Cime HC ( $n=5)$, Cago $H C(n=5)$, Coce HC $(n=10)$, Detu kersu HC $(n=6)$, Dabo yaya HC $(n=6)$, Doyo HC $(n=4)$, Darge HC $(n=5)$ Edo hidhata HC $(n=6)$, Gembe HC $(n=13)$, Getashewa HC $(n=7)$, Guyo HC $(n=7)$, Haro HC ( $n=7)$, Jimate HC ( $n=3)$, Jimma HC $(n=2 I)$, Jimma University Medical center $(n=74)$, Kore HC ( $=3)$, Korjo HC $(n=4)$, Kusaye HC ( $=4)$, Maxoso HC (n=7), Mole HC ( $n=11)$, Limmu genet HC $(n=12)$, Limu Shaye HC $(n=5)$, Omo gurude HC $(n=4)$, Ofkole HC ( $n=7)$, Seka HC ( $=8)$, Serbo HC ( $=18)$, Sokorru $H C(n=20)$, Sheki HC $(n=16)$, Yaci HC $(n=6)$, Yabu HC $(n=11)$.

Abbreviations: HC, Health center; HO, Hospital.

level of social support. It was found reliable (Cronbach $\alpha=$ 0.84 ) in the current study. Score from 3-8 was considered as poor, 9-11 moderate, and 12-14 strong social support. ${ }^{16}$

Perceived TB stigma was assessed by 11 item perceived TB stigma scale which was adopted from Somma et al. ${ }^{20}$ Participants were considered to have perceived stigma if they scored above or equal to the mean stigma score of the study population. ${ }^{21,22}$ It had cronbach $\alpha=0.78$ in the current study. Perceived stress level was assessed by 10 item perceived stress scale. In the current study it had cronbach $\alpha=$ 0.80 . Score from $0-15$ was considered low to average perceived stress and score $\geq 16$ high perceived stress. ${ }^{23}$

Depression and anxiety were assessed by HADS: 14-item questionnaire commonly used to screen for symptoms of anxiety and depression. The 14 items can be separated into two 7 item sub-scales for anxiety (HAD-A) and depression (HAD-D). It was validated in Ethiopia and its internal consistency was 0.78 for anxiety, 0.76 for depression subscales, and 0.87 for full scale. ${ }^{24}$ In the current study HAD-A had cronbach $\alpha=0.81$, it was 0.82 for HAD-D and 0.89 for full scale. A score $\geq 8$ on separated HAD-A subscale and HAD-D was considered as probable case of anxiety and depression respectively. ${ }^{24}$

Presence of comorbid chronic illness (at least one from HIV-AIDS, hypertension, diabetic mellitus, epilepsy and asthma) was assessed by structured questionnaire and extracted from the patient chart after informed consent.
Duration of illness (the time duration of TB symptoms before the diagnosis of TB) was assessed by asking the patient how long TB symptoms lasted before the illness was diagnosed as TB. Substance use risk level was assessed by using WHO Alcohol, Smoking and Substance Involvement Screening Test (ASSIST v3.1). The ASSIST risk score ranges from 0 to 31 for tobacco and 0-39 for alcohol, cannabis and khat (stimulant), alcohol low risk score from $0-10$, moderate $11-26$, and high risk $\geq 27$. The risk scores for khat, tobacco and cannabis were similar; low (0 to 3 ), moderate ( 4 to 26 ) and high ( $\geq 27) .{ }^{25}$ In the current study for alcohol, tobacco and cannabis the risk was categorized into risk exists (ever used in their life) and risk does not exist due to small sample in the category, and the risk level for khat was defined as low risk $0-3$, moderate to high $\geq 4$. ${ }^{25}$

\section{Study Variables}

The outcome variables were depression and anxiety. Explanatory variables were age, sex, marital status, educational status, religion, occupation, place of residence, family size, perceived social support, perceived stress level, perceived TB stigma, duration of TB illness, phase of treatment, body mass index (BMI), category of treatment, family history of mental illness, comorbid chronic illness, alcohol use risk, tobacco use risk, khat use risk, and cannabis use risk. 


\section{Data Quality Assurance}

To ensure the quality of data, all instruments were translated to Afaan Oromo and Amharic language and a pretest was performed on $20(5 \%)$ of the TB patients being followed-up at Shenen Gibe Hospital and Bacho Bore Health Center which was not part of the study population. Training on data collection instrument and data handling was provided to data collectors and supervisors.

\section{Data Processing and Analyses}

Data were entered into Epi data v3.1 and analyzed by SPSS v23. Bivariate binary logistic regression was performed to each independent variable with the outcome variable. Explanatory variables with $\mathrm{p}$-value $\leq 0.25$ in the bivariate analysis were candidates for multivariate logistic regression. Multivariate logistic regression model was done and adjusted odds ratio with 95\% CI was calculated to identify the independent association of each variable. $\mathrm{P}$-value $<0.05$ was considered statistically significant.

\section{Ethical Consideration}

Ethical clearance was obtained from the Research and Ethics Review board Committee of Jimma University Institute of Health. Letter of permission was obtained from Jimma zone health department and relevant woreda health bureau. Written informed consent was obtained from each participant after they were informed about the aims of the study, voluntary participation and the right to withdraw at any time. Participants' right to refuse or discontinue the interview at any time they wanted to was strictly respected. Information taken from participants was kept confidential at all levels of the study. Patients who were found to have severe depression and/or anxiety were linked to psychiatry clinic in Jimma university medical center.

\section{Results}

\section{Socio-Demographic Characteristics of the Study Participants}

A total of 410 participants were enrolled in the study which resulted in an overall response rate of $99.03 \%$. Two hundred and eleven $(51.5 \%)$ were male. The mean age of the respondents was $31.85(\mathrm{SD}=12.42)$ years. The majority, 215 $(52.4 \%)$, were married and about 214 (52.2\%) were from urban areas (concerning to their place of residence, Table 1).
Table I Socio-Demographic Characteristics of Pulmonary Tuberculosis Patients at Public Health Facilities in Jimma Zone, Southwest Ethiopia, $2019(\mathrm{~N}=410)$

\begin{tabular}{|c|c|c|c|}
\hline Variables & Category & $\begin{array}{l}\text { Frequency } \\
\text { (N) }\end{array}$ & $\begin{array}{l}\text { Percent } \\
\text { (\%) }\end{array}$ \\
\hline Age & $\begin{array}{l}18-24 \\
25-34 \\
35-44 \\
45-54 \\
\geq 55\end{array}$ & $\begin{array}{l}132 \\
145 \\
57 \\
46 \\
30\end{array}$ & $\begin{array}{l}32.2 \\
35.4 \\
13.9 \\
11.2 \\
7.3\end{array}$ \\
\hline $\begin{array}{l}\text { Marital } \\
\text { Status }\end{array}$ & $\begin{array}{l}\text { Single } \\
\text { Married } \\
\text { Divorced } \\
\text { Widowed }\end{array}$ & $\begin{array}{l}149 \\
215 \\
31 \\
15\end{array}$ & $\begin{array}{l}36.3 \\
52.4 \\
7.6 \\
3.7\end{array}$ \\
\hline Religion & $\begin{array}{l}\text { Muslim } \\
\text { Orthodox } \\
\text { Protestant }\end{array}$ & $\begin{array}{l}257 \\
113 \\
40\end{array}$ & $\begin{array}{l}62.7 \\
27.6 \\
9.8\end{array}$ \\
\hline $\begin{array}{l}\text { Educational } \\
\text { Status }\end{array}$ & $\begin{array}{l}\text { No formal education } \\
\text { Primary }(1-8) \\
\text { Secondary }(9-12) \\
\text { College and above }\end{array}$ & $\begin{array}{l}90 \\
147 \\
109 \\
64\end{array}$ & $\begin{array}{l}22.00 \\
35.9 \\
26.6 \\
15.6\end{array}$ \\
\hline Occupation & $\begin{array}{l}\text { Daily laborer } \\
\text { Farmer } \\
\text { Government employee } \\
\text { Merchant } \\
\text { Student } \\
\text { Housewife } \\
\text { Non-government } \\
\text { organization/private } \\
\text { employee }\end{array}$ & $\begin{array}{l}56 \\
87 \\
53 \\
38 \\
59 \\
69 \\
48\end{array}$ & $\begin{array}{l}13.7 \\
21.2 \\
12.9 \\
9.3 \\
14.4 \\
16.8 \\
11.7\end{array}$ \\
\hline Family Size & $\begin{array}{l}\leq 5 \\
>5\end{array}$ & $\begin{array}{l}358 \\
52\end{array}$ & $\begin{array}{l}87.3 \\
12.7\end{array}$ \\
\hline
\end{tabular}

\section{Clinical, Psychosocial and Substance Use Related Characteristics}

The majority, 379 (92.4\%), were in new TB treatment category. Two hundred and twenty two (54.1\%) were in an intensive phase of TB treatment. Over half, 234 (57.1\%), were reported to have perceived stigma. The majority, 223 (54.4\%), reported high perceived stress. More than half, 217 (52.9\%), had khat use risk (Table 2).

\section{Prevalence of Depression and Anxiety Among PTB Patients}

Prevalence of depression and anxiety among PTB patients were $55.9 \%$ (95\% CI 51.0, 60.7) and 54.6\% (95\% CI 50.0, 59.5) respectively. More females, 132 (66.3\%), than males, $97(46.0 \%)$, were found to have depression. 
Table 2 Clinical, Psycho-Social and Substance Use Risk-Related Factors of PTB Patients on Follow-Up at Public Health Facilities in Jimma Zone, Southwest Ethiopia, $2019(n=410)$

\begin{tabular}{|c|c|c|c|}
\hline Variable & Category & Frequency $(\mathbf{N})$ & $\begin{array}{l}\text { Percent } \\
\text { (\%) }\end{array}$ \\
\hline $\begin{array}{l}\text { Category of } \\
\text { Treatment }\end{array}$ & $\begin{array}{l}\text { New } \\
\text { Return after } \\
\text { default } \\
\text { Relapse/re- } \\
\text { treatment }\end{array}$ & $\begin{array}{l}379 \\
10 \\
21\end{array}$ & $\begin{array}{l}92.4 \\
2.4 \\
5.1\end{array}$ \\
\hline Duration of Illness & $\begin{array}{l}\leq 4 \text { weeks } \\
>4 \text { weeks }\end{array}$ & $\begin{array}{l}279 \\
131\end{array}$ & $\begin{array}{l}68.0 \\
32.0\end{array}$ \\
\hline $\begin{array}{l}\text { Comorbid HIV- } \\
\text { AIDS }\end{array}$ & $\begin{array}{l}\text { Yes } \\
\text { No }\end{array}$ & $\begin{array}{l}86 \\
324\end{array}$ & $\begin{array}{l}21.0 \\
79.0\end{array}$ \\
\hline Other Comorbidity & $\begin{array}{l}\text { Yes } \\
\text { No }\end{array}$ & $\begin{array}{l}26 \\
384\end{array}$ & $\begin{array}{l}6.3 \\
93.7\end{array}$ \\
\hline $\begin{array}{l}\text { Family History of } \\
\text { Mental Illness }\end{array}$ & $\begin{array}{l}\text { Yes } \\
\text { No }\end{array}$ & $\begin{array}{l}87 \\
323\end{array}$ & $\begin{array}{l}21.2 \\
78.8\end{array}$ \\
\hline Body Mass Index & $\begin{array}{l}\text { Low BMI } \\
\text { Not low BMI }\end{array}$ & $\begin{array}{l}182 \\
228\end{array}$ & $\begin{array}{l}44.4 \\
55.6\end{array}$ \\
\hline $\begin{array}{l}\text { Level of Social } \\
\text { Support }\end{array}$ & $\begin{array}{l}\text { Poor } \\
\text { Moderate } \\
\text { Strong }\end{array}$ & $\begin{array}{l}171 \\
168 \\
71\end{array}$ & $\begin{array}{l}41.7 \\
41.0 \\
17.3\end{array}$ \\
\hline $\begin{array}{l}\text { Perceived TB } \\
\text { Stigma }\end{array}$ & $\begin{array}{l}\text { Yes } \\
\text { No }\end{array}$ & $\begin{array}{l}234 \\
176\end{array}$ & $\begin{array}{l}57.1 \\
42.9\end{array}$ \\
\hline Perceived Stress & $\begin{array}{l}\text { Low to } \\
\text { average } \\
\text { High }\end{array}$ & $\begin{array}{l}187 \\
223\end{array}$ & $\begin{array}{r}45.6 \\
54.4\end{array}$ \\
\hline Tobacco Use Risk & $\begin{array}{l}\text { No risk } \\
\text { Risk exists }\end{array}$ & $\begin{array}{l}389 \\
21\end{array}$ & $\begin{array}{l}94.9 \\
5.1\end{array}$ \\
\hline Alcohol Use Risk & $\begin{array}{l}\text { No risk } \\
\text { Risk exists }\end{array}$ & $\begin{array}{l}320 \\
90\end{array}$ & $\begin{array}{l}78.0 \\
22.0\end{array}$ \\
\hline Cannabis Use Risk & $\begin{array}{l}\text { No risk } \\
\text { Risk exists }\end{array}$ & $\begin{array}{l}392 \\
18\end{array}$ & $\begin{array}{l}95.6 \\
4.4\end{array}$ \\
\hline Khat Use Risk & $\begin{array}{l}\text { No risk } \\
\text { Low } \\
\text { Moderate to } \\
\text { high }\end{array}$ & $\begin{array}{l}193 \\
60 \\
157\end{array}$ & $\begin{array}{l}47.1 \\
14.6 \\
38.3\end{array}$ \\
\hline
\end{tabular}

Note: Other comorbidity, hypertension/diabetic mellitus/asthma/epilepsy. Abbreviation: BMl, body mass index.

Depression was higher among those who reported to have poor social support, 135 (78.9\%), and perceived stigma, $194(82.9 \%)$, than their counterparts. Anxiety was also higher among females, 137 (68.8\%), those who reported to have perceived stigma, $180(76.9 \%)$, and poor social support, $130(76.0 \%)$, than their counterparts.

\section{Factors Associated with Depression Among PTB Patients}

After adjusting for confounding variables, the odds of having depression was 3.6 times higher among PTB patients who reported high perceived stress $[\mathrm{AOR}=3.61$ $95 \%$ CI $(1.99,6.53)]$ than those who reported low to average perceived stress. Depression was 3.3 times higher among PTB patients in an intensive phase of treatment $[\mathrm{AOR}=3.3395 \% \mathrm{CI}(1.83,6.07)]$.

It was found that perceived $\mathrm{TB}$ stigma $[\mathrm{AOR}=10.13$ $95 \% \mathrm{CI}(5.52,18.63)]$, no formal education $[\mathrm{AOR}=3.03$ $95 \%$ CI $(1.12,8.23)]$, and low body mass index [AOR $=2.07$ 95\% CI $(1.13,3.80)]$ had significant association with depression. Strong social support $[\mathrm{AOR}=0.21$ $95 \%$ CI $(0.08,0.51)]$ was found to be a protective factor (Table 3).

\section{Factors Associated with Anxiety Among PTB Patients}

Multivariate logistic regression analysis revealed that the odds of having anxiety among females were 2.4 times higher $[\mathrm{AOR}=2.4295 \% \mathrm{CI}(1.39,4.23)]$ than in males. High perceived stress was 4.40 times more likely [AOR $=4.4095 \% \mathrm{CI}(2.52,7.69)]$ to be associated with anxiety. Anxiety was 3.5 times higher [AOR $=3.5895 \% \mathrm{CI}(1.99$, 6.42)] among PTB patients who were found to have perceived TB stigma than in their counterparts. Patients with family history of mental illness were about 2.6 times more likely $[\mathrm{AOR}=2.6695 \% \mathrm{CI}(1.19,5.94)]$ to have anxiety than their counterparts. Low body mass index [AOR = $1.8395 \% \mathrm{CI}(1.02,3.28)]$ and being in an intensive phase of TB treatment $[\mathrm{AOR}=2.8995 \% \mathrm{CI}(1.62,5.14)]$ were significantly associated with anxiety (Table 4 ).

\section{Discussion}

\section{Prevalence of Depression Among PTB Patients}

The finding revealed that a high proportion of PTB patients on follow-up treatment had probable depression. A similar finding was reported from previous studies carried out in Southern (54\%) and Eastern Ethiopia $(51.9 \%),{ }^{16,17}$ in southwest Cameroon $(61.1 \%),{ }^{26}$ in Pakistan $(56 \%),{ }^{3}$ and Turkey $(60.5 \%) .{ }^{8} \mathrm{~A}$ higher proportion of depression than that of the current study was reported from two studies carried out in Pakistan $(72.2 \%, 80 \%) .{ }^{6,27}$ The discrepancy might in part be due to difference in study setting, population studied, and 
Table 3 Bivariate and Multivariate Logistic Regression Analyses of Factors Associated with Depression Among PTB Patients in Jimma Zone, Southwest Ethiopia, $2019(n=410)$

\begin{tabular}{|c|c|c|c|c|c|c|}
\hline \multirow[t]{2}{*}{ Variables } & \multirow[t]{2}{*}{ Category } & \multicolumn{2}{|l|}{ Depression } & \multirow[t]{2}{*}{ COR, 95\% (Cl) } & \multirow[t]{2}{*}{ AOR, $95 \%(\mathrm{Cl})$} & \multirow[t]{2}{*}{ P-value } \\
\hline & & Yes N (\%) & No N (\%) & & & \\
\hline \multirow[t]{2}{*}{ Sex } & Male & $97(46.0)$ & II 4(54.0) & I & I & \\
\hline & Female & $132(66.3)$ & $67(33.7)$ & $2.31(1.55,3.45)$ & $1.10(0.56,2.13)$ & 0.797 \\
\hline \multirow[t]{5}{*}{ Age } & $18-24$ & $60(45.5)$ & $72(54.5)$ & 1 & I & \\
\hline & $25-34$ & $8 I(55.9)$ & $64(44.1)$ & $1.52(0.94,2.44)$ & I.I8 $(0.56,2.5 \mathrm{I})$ & 0.660 \\
\hline & $35-44$ & $37(64.9)$ & $20(35.1)$ & $2.22(1.17,4.22)$ & I.I5 (0.4I, 3.24) & 0.789 \\
\hline & $45-54$ & $32(69.6)$ & 14(30.4) & $2.74(I .34,5.6 I)$ & $0.90(0.30,2.68)$ & 0.856 \\
\hline & $\geq 55$ & $19(63.3)$ & II(36.7) & 2.07 (0.9I, 4.69) & $0.44(0.13,1.54)$ & 0.199 \\
\hline \multirow[t]{2}{*}{ Residence } & Rural & $119(60.7)$ & $77(39.3)$ & $1.46(0.98,2.16)$ & I.7I $(0.87,3.33)$ & 0.116 \\
\hline & Urban & $110(51.4)$ & $104(48.6)$ & 1 & 1 & \\
\hline \multirow[t]{4}{*}{ Educational Status } & No formal education & $70(77.8)$ & $20(22.2)$ & $5.83(2.87,11.85)$ & $3.03(1.12,8.23)$ & 0.030 \\
\hline & Primary & $92(62.6)$ & $55(37.4)$ & $2.78(1.52,5.11)$ & $1.67(0.70,3.94)$ & $0.24 I$ \\
\hline & Secondary & $43(39.4)$ & $66(60.6)$ & $1.08(0.57,2.05)$ & $0.64(0.25,1.64)$ & 0.349 \\
\hline & College and above & $24(37.5)$ & $40(62.5)$ & 1 & 1 & \\
\hline \multirow[t]{3}{*}{ Social Support } & Poor & $135(78.9)$ & $36(21.1)$ & I & I & \\
\hline & Moderate & $79(47.0)$ & $89(53.0)$ & $0.24(0.15,0.38)$ & $0.68(0.35,1.33)$ & 0.260 \\
\hline & Strong & $15(21.1)$ & $56(78.9)$ & $0.07(0.03,0.14)$ & $0.2 I(0.08,0.5 I)$ & 0.001 \\
\hline \multirow[t]{2}{*}{ Treatment Phase } & Intensive & $172(77.5)$ & $50(22.5)$ & $7.90(5.08,12.31)$ & $3.33(1.83,6.07)$ & $0.001^{*}$ \\
\hline & Continuation & $57(30.3)$ & $|3|(69.7)$ & I & I & \\
\hline \multirow[t]{2}{*}{ Duration of Illness } & $\leq 4$ weeks & $139(49.8)$ & $140(50.2)$ & I & I & \\
\hline & $>4$ weeks & $90(68.7)$ & $4 I(3 I .3)$ & $2.21(1.43,3.42)$ & I.II $(0.55,2.24)$ & 0.770 \\
\hline \multirow[t]{2}{*}{ Comorbid HIV-AIDS } & Yes & $70(81.4)$ & $16(18.6)$ & $4.54(2.53,8.15)$ & $1.36(0.59,3.11)$ & 0.465 \\
\hline & No & $159(49.1)$ & $165(50.9)$ & I & 1 & \\
\hline \multirow[t]{2}{*}{ Other Comorbidity } & Yes & $21(80.8)$ & $5(19.2)$ & $3.55(1.31,9.62)$ & $0.87(0.24,3.16)$ & 0.829 \\
\hline & No & $208(54.2)$ & $176(45.8)$ & I & 1 & \\
\hline \multirow[t]{2}{*}{ Body Mass Index } & Low BMI & $133(73.1)$ & $49(26.9)$ & $3.73(2.45,5.68)$ & $2.07(1.13,3.80)$ & 0.019 \\
\hline & Not low BMI & $96(42.1)$ & $132(57.9)$ & I & 1 & \\
\hline \multirow[t]{2}{*}{ Perceived Stigma } & No & $35(19.9)$ & $|4|(80.1)$ & I & 1 & $0.001 *$ \\
\hline & Yes & $194(82.9)$ & $40(17.1)$ & $19.54(\mid 1.82,32.30)$ & $10.13(5.52,18.63)$ & \\
\hline \multirow[t]{2}{*}{ Perceived Stress } & Low to average & $57(30.5)$ & $130(69.5)$ & 1 & I & $0.001 *$ \\
\hline & High & $172(77.1)$ & $5 I(22.9)$ & $7.69(4.95,11.96)$ & $3.61(1.99,6.53)$ & \\
\hline \multirow[t]{3}{*}{ Khat Use Risk } & No risk & $95(49.2)$ & $98(50.8)$ & I & 1 & \\
\hline & Low & $26(43.3)$ & $34(56.7)$ & $0.79(0.44, I .4 \mathrm{I})$ & $0.46(0.17,1.24)$ & 0.127 \\
\hline & Moderate to high & $108(68.8)$ & $49(31.2)$ & $2.27(1.46,3.53)$ & $1.21(0.63,2.32)$ & 0.558 \\
\hline
\end{tabular}

Notes: I, reference category; other comorbidity, hypertension/diabetes mellitus/asthma/epilepsy; ${ }^{*} \mathrm{p}<0.00 \mathrm{I}$ Hosmer-Lemeshow test $=0.89$.

Abbreviations: COR, crude odds ratio; AOR, adjusted odds ratio; BMI, body mass index.

screening instrument used. One study ${ }^{6}$ included only a sample of newly diagnosed PTB patients and furthermore, the other study ${ }^{27}$ included only smear-positive PTB patients and used Hamilton depression rating scale.

On the other hand, this finding was higher than that of a study done in Walaita Sodo (43.4\%), Jimma (19.8\%), and Addis Ababa (31.1\%) Ethiopia. ${ }^{11,13,15}$ A possible reason for the discrepancy may be explained in part due to the difference in the screening instrument used and the difference in the population studied. Only one study ${ }^{13}$ used the same screening instrument as the present study. The discrepancy in prevalence with this study may be attributed to 
types of TB patients addressed. Unlike that of previous study, the current study included only patients with PTB, the one known to be contagious and life threatening, and the evolving stress contributes to greater risk of emotional problems. $^{8}$

\section{Prevalence of Anxiety Among Patients with PTB}

The study also shows that a higher proportion of PTB patients suffered from probable anxiety. A similar finding was reported from Pakistan $(65 \%)^{3}$ and India (54\%). A study carried out in Haripur ${ }^{6}$ found an even higher prevalence rate $(72.2 \%)$ than the current study, which may be attributed to the difference in patients studied. Unlike the current study, patients with MDR-TB (more stigmatized condition associated with poorer prognosis) were included.

On the other hand, a lower prevalence rate than that of the current study was reported from Walaita Sodo Ethiopia $(41.5 \%)^{13}$ despite the same tool being used. The variation may be due to the difference in patients and setting of the study - the previous study had male predominance and comprised only a sample from urban areas, which may have better access to health service resources. A lower prevalence rate than that of the current study was also reported from Turkey $(26 \%){ }^{8}$ Differences in cutoff point$\mathrm{s}$ using HADS $\geq 10^{8}$ may account for the difference.

\section{Factors Associated with Depression Among PTB Patients}

Study revealed that depression was about 79\% less likely among PTB patients who had strong social support than in those who had poor social support. The finding is in line with other studies. ${ }^{11,13,16}$ Poor social support gives patients a feeling of being neglected, isolated and worthless, and in contrast strong social support is vital for prevention of such feelings. ${ }^{14}$ Being in an intensive phase of TB treatment was significantly associated with depression, this finding is in line with other studies. ${ }^{28,29}$ This might be related to severity of illness as symptoms of TB tend to be more prominent during intensive phase and likely to improve over time during continuation phase. ${ }^{19,28}$

In agreement with other studies, ${ }^{10,11,13}$ patients with PTB who had perceived TB stigma were more likely to be depressed than their counterparts. This might be related to the fact that social acceptance of patients with PTB may be compromised and further negative reactions from others may interfere with their sense of self-confidence which may later end-up in emotional problems. ${ }^{8,13}$ In line with studies carried out in Ethiopia, Philippines, Taiwan, and China ${ }^{10,16,30,31}$ low body mass index was significantly associated with depression. This may be because under-nutrition weakens the immune system, thus the ability of the individual to fight infection and to control disease progression is compromised. ${ }^{32}$

Furthermore, in agreement with the study from northeast Ethiopia, ${ }^{34}$ which reported that no formal education had a significant association with common mental disorders, having no formal education was found to have a significant association with depression in the current study. This could be explained, in part, by the fact that having no formal education may prevent an individual from accessing most professional jobs and visiting healthcare facilities, and contributes to persistently low social resources.

In contrast to this, a higher level of education leads to better income, proper adaptation to treatment, and access to a wide range of health services. ${ }^{14,16,34}$ High perceived stress was significantly associated with depression. This may be explained, in part, by the fact that having high perceived stress may also lead to negative coping behaviors such as substance use and unhealthy dieting. ${ }^{35}$

\section{Factors Associated with Anxiety Among PTB Patients}

In agreement with another study, ${ }^{13}$ being female was 2.4 times more likely to be associated with anxiety. Biological factors like hormonal fluctuation with pregnancy and menstruation and social factors like burden of household responsibilities may contribute to the higher prevalence of anxiety among females than males. ${ }^{3,4,34}$ Being in intensive phase of treatment was 2.89 times more likely to have a significant association with anxiety. It can be said that patients recently diagnosed with TB might have anxiety immediately upon learning their diagnosis, ${ }^{14}$ and symptoms related to TB disease tend to be prominent and are less likely to decrease within 1-2 months of treatment initiation. $^{15,19}$ A similar finding was also reported from a previous study. ${ }^{13}$

Consistent with another study, ${ }^{13}$ anxiety was about 3.58 times higher among patients who reported to have perceived stigma than those who had not reported perceived stigma. Studies have demonstrated that presence of perceived stigma is highly associated with psychological distress. TB patients who have perceived stigma may be socially isolated because of fear of transmitting disease 
Table 4 Bivariate and Multivariate Logistic Regression Analyses of Factors Associated with Anxiety Among PTB Patients in Jimma Zone, Southwest Ethiopia, 2019 ( $N=410)$

\begin{tabular}{|c|c|c|c|c|c|c|}
\hline \multirow[t]{2}{*}{ Variables } & \multirow[t]{2}{*}{ Category } & \multicolumn{2}{|l|}{ Anxiety } & \multirow[t]{2}{*}{ COR, $95 \%(\mathrm{Cl})$} & \multirow[t]{2}{*}{ AOR, $95 \%(\mathrm{Cl})$} & \multirow[t]{2}{*}{ P-value } \\
\hline & & Yes N (\%) & No N (\%) & & & \\
\hline Sex & $\begin{array}{l}\text { Male } \\
\text { Female }\end{array}$ & $\begin{array}{l}87(41.2) \\
137(68.8)\end{array}$ & $\begin{array}{l}124(58.8) \\
62(31.2)\end{array}$ & $\begin{array}{l}\text { I } \\
3.15(2.09,4.73)\end{array}$ & $\begin{array}{l}\text { I } \\
2.42(1.39,4.23)\end{array}$ & 0.002 \\
\hline Age & $\begin{array}{l}18-24 \\
25-34 \\
35-44 \\
45-54 \\
\geq 55\end{array}$ & $\begin{array}{l}59(44.7) \\
80(55.2) \\
38(66.7) \\
28(60.9) \\
19(63.3)\end{array}$ & $\begin{array}{l}73(55.3) \\
65(44.8) \\
19(33.3) \\
18(39.1) \\
11(36.7)\end{array}$ & $\begin{array}{l}\text { I } \\
\text { I.52 }(0.95,2.45) \\
2.47(1.29,4.73) \\
\text { I.92 }(0.97,3.82) \\
2.14(0.94,4.84)\end{array}$ & $\begin{array}{l}\text { I } \\
\text { I.27(0.63, 2.60) } \\
\text { I.49(0.54, 4.15) } \\
0.65(0.23,1.83) \\
0.70(0.2 \mathrm{I}, 2.35)\end{array}$ & $\begin{array}{l}0.509 \\
0.442 \\
0.425 \\
0.572\end{array}$ \\
\hline Level of Social Support & $\begin{array}{l}\text { Poor } \\
\text { Moderate } \\
\text { Strong }\end{array}$ & $\begin{array}{l}130(76.0) \\
77(45.8) \\
17(23.9)\end{array}$ & $\begin{array}{l}41(24.0) \\
91(54.2) \\
54(76.1)\end{array}$ & $\begin{array}{l}\text { I } \\
0.26(0.17,0.42) \\
0.09(0.05,0.19)\end{array}$ & $\begin{array}{l}\text { I } \\
0.69(0.37,1.29) \\
0.30(0.13,0.69)\end{array}$ & $\begin{array}{l}0.250 \\
0.005\end{array}$ \\
\hline Phase of Treatment & $\begin{array}{l}\text { Intensive } \\
\text { Continuation }\end{array}$ & $\begin{array}{l}168(75.7) \\
56(29.8)\end{array}$ & $\begin{array}{l}54(24.3) \\
132(70.2)\end{array}$ & $\begin{array}{l}7.33(4.73, \text { II.36) } \\
\text { I }\end{array}$ & $\begin{array}{l}2.89(1.62,5.14) \\
1\end{array}$ & $0.001 *$ \\
\hline Duration of Illness & $\begin{array}{l}\leq 4 \text { weeks } \\
>4 \text { weeks }\end{array}$ & $\begin{array}{l}132(47.3) \\
92(70.2)\end{array}$ & $\begin{array}{l}147(52.7) \\
39(29.8)\end{array}$ & $2.63(1.68,4.10)$ & $\begin{array}{l}\text { I } \\
\text { I.86 }(0.98,3.52)\end{array}$ & 0.054 \\
\hline Comorbid HIV-AIDS & $\begin{array}{l}\text { Yes } \\
\text { No }\end{array}$ & $\begin{array}{l}66(76.7) \\
158(48.8)\end{array}$ & $\begin{array}{l}20(23.3) \\
166(51.2)\end{array}$ & $\begin{array}{l}3.47(2.01,5.98) \\
I\end{array}$ & $\begin{array}{l}1.09(0.49,2.45) \\
\text { I }\end{array}$ & 0.825 \\
\hline $\begin{array}{l}\text { Family History } \\
\text { of Mental Illness }\end{array}$ & $\begin{array}{l}\text { Yes } \\
\text { No }\end{array}$ & $\begin{array}{l}76(87.4) \\
148(45.8)\end{array}$ & $\begin{array}{l}\mathrm{II}(12.6) \\
\mathrm{I} 75(54.2)\end{array}$ & $\begin{array}{l}8.17(4.18,15.95) \\
\text { I }\end{array}$ & $\begin{array}{l}2.66(1.19,5.94) \\
1\end{array}$ & 0.016 \\
\hline BMI & $\begin{array}{l}\text { Low BMI } \\
\text { Not low BMI }\end{array}$ & $\begin{array}{l}132(72.5) \\
92(40.4)\end{array}$ & $\begin{array}{l}50(27.5) \\
136(59.6)\end{array}$ & $\begin{array}{l}3.90(2.56,5.94) \\
I\end{array}$ & $\begin{array}{l}1.83(1.02,3.28) \\
\text { I }\end{array}$ & 0.042 \\
\hline Perceived Stigma & $\begin{array}{l}\text { No } \\
\text { Yes }\end{array}$ & $\begin{array}{l}44(25.0) \\
180(76.9)\end{array}$ & $\begin{array}{l}132(75.0) \\
54(23.1)\end{array}$ & $\begin{array}{l}\text { I } \\
10.0(6.33,15.79)\end{array}$ & $\begin{array}{l}\text { I } \\
3.58(1.99,6.42)\end{array}$ & $0.001 *$ \\
\hline Perceived Stress & $\begin{array}{l}\text { Low to average } \\
\text { High }\end{array}$ & $\begin{array}{l}52(27.8) \\
172(77.1)\end{array}$ & $\begin{array}{l}135(72.2) \\
51(22.9)\end{array}$ & $\begin{array}{l}\text { I } \\
8.75(5.59,13.69)\end{array}$ & $\begin{array}{l}\text { I } \\
4.40(2.52,7.69)\end{array}$ & $0.00 I^{*}$ \\
\hline Khat Use Risk & $\begin{array}{l}\text { No risk } \\
\text { Low risk } \\
\text { Moderate to high }\end{array}$ & $\begin{array}{l}98(50.8) \\
26(43.3) \\
100(63.7)\end{array}$ & $\begin{array}{l}95(49.2) \\
34(56.7) \\
57(36.3)\end{array}$ & $\begin{array}{l}\text { I } \\
0.74(0.41,1.33) \\
1.70(I .10,2.62)\end{array}$ & $\begin{array}{l}\text { I } \\
0.57(0.22, I .48) \\
0.92(0.45,1.84)\end{array}$ & $\begin{array}{l}0.251 \\
0.812\end{array}$ \\
\hline
\end{tabular}

Notes: I, reference category; ${ }^{*} \mathrm{p}<0.001$ Hosmer-Lemeshow test $=0.65$.

and may have a low self-image, this may predispose them to anxiety. $8,10,12,13,18,36$

The study demonstrated that PTB patients with a family history of mental illness were 2.66 times more likely to have anxiety than their counterparts. Although we were not able to find a satisfactorily similar study to compare to this finding, previously reported studies showed an association between family history of mental illness and common mental disorders. $^{34}$

This could be attributed to biological factors, eg, genetic studies have shown strong evidence that genetic components contribute to the development of anxiety disorders. ${ }^{33}$
Anxiety was significantly lower among patients who reported to have strong social support than in patients who had poor social support. This may be related to the fact that a poor social support system gives patients a feeling of being neglected, isolated and worthless, and in contrast strong social support is vital for prevention of such feelings. ${ }^{14}$

Furthermore, this study revealed that high perceived stress was significantly associated with anxiety. This could be related to the fact that stress is known to cause dysregulation of the hypothalamic-pituitary-adrenal axis which may lead to changes in cortisol levels, immune system response, and cortical reactivity. ${ }^{35}$ 


\section{Strengths and Limitations of the Study}

Standard tools were used to assess the associated variables; perceived stress level, perceived level of social support, substance use and perceived TB stigma. Given that there is overlap between somatic symptoms of depression and TB symptoms, a validated tool which excludes somatic symptoms was utilized in this study. In addition, this study addressed potential confounding variables like perceived stress level, which was not covered by other previous studies.

Furthermore, the study used a representative sample from multiple sites, the result can be generalized to PTB patients being followed-up in a similar setting. However, the study has some limitations: only probable prevalence of anxiety and depression was assessed as a screening rather than diagnostic tool was utilized. Since the study was conducted using face-to-face interviews, there may be a possibility of social desirability bias. Possibility of recall bias exists as some of the factors were assessed based on past history.

Furthermore, important factors such as perceived severity of TB symptoms, medication adherence, and side effects of anti-TB medications were not addressed in this study.

\section{Conclusion}

More than half of the study participants were found to have probable depression and anxiety. Perceived stigma, high perceived stress, being in an intensive phase of treatment, and low BMI were significantly associated with both depression and anxiety. This indicates the need to pay attention to the mental health conditions of patients with PTB, particularly to those with identified risk factors.

\section{Data Sharing Statement}

The data-sets used and/or analyzed in the current study are included in the manuscript.

\section{Ethics Approval and Consent to Participate}

The study was carried out in accordance with the principles of the Declaration of Helsinki. Ethical clearance was obtained from the Research and Ethics Review Board Committee of Jimma University, Institute of Health. Written informed consent was obtained from each study participant after they were informed about the aims of the study, voluntary participation and the right to withdraw at any time. Participants' right to refuse or discontinue participation at any time they want was strictly respected. Confidentiality was maintained at all levels of the study.

\section{Acknowledgments}

The authors acknowledge Jimma University Institute of Health for financial support. Data collectors and study participants are also highly acknowledged.

\section{Author Contributions}

All authors were involved in the inception of the idea, contributed to the design, data analysis and interpretation and write-up of the manuscript. All authors contributed to data analysis, drafting or revising the article, gave final approval of the version to be published, and agree to be accountable for all aspects of the work.

\section{Funding}

This research work is funded by Jimma University Institute of Health. The funding body had no role in the design of the study, data collection, analysis, interpretation of the data or writing of the manuscript.

\section{Disclosure}

The authors report no conflicts of interest in this work.

\section{References}

1. World Health Organization. Depression and Other Common Mental Disorders. Geneva: Global Health Estimates; 2017.

2. World Health Organization (WHO). Global tuberculosis report,2018 [Internet]. Geneva: World Health Organization; 2018. Available from: http://apps.who.int/iris.

3. Rizvi N. Frequency of depression and anxiety among tuberculosis patients. J Tuberc Res. 2016;4:183-190. doi:10.4236/jtr.2016.44021

4. Pradesh H, Pradesh H, Pradesh H, et al. Assessment of the frequency of depression and anxiety among tuberculosis patients at a tertiary care health centre a cross. Eur J Pharm Med Res. 2018;5(4):496-499.

5. Pachi A, Bratis D, Moussas G, Tselebis A. Psychiatric morbidity and other factors affecting treatment adherence in pulmonary tuberculosis patients. Hindawi Publ Corp Tuberc Res Treat. 2013;2013.

6. Aamir SA. Co-morbid anxiety and depression among PTB patients. J Coll Physicians Surg. 2010;20:703-704.

7. Paula A, Lazzari TK, Silva DR. Health-related quality of life, depression and anxiety in hospitalized patients with tuberculosis. Tuberc Respir Dis. 2017;80:69-76. doi:10.4046/trd.2017.80.1.69

8. Yilmaz A, Dedelı O. Assessment of anxiety, depression, lonelıness and stigmatization in patients with tuberculosis. Acta Paul Enferm. 2016;29(5):549-557. doi:10.1590/1982-0194201600076

9. Sweetland AC, Kritski A, Oquendo MA, et al. Addressing the tuberculosis-depression syndemic to end the tuberculosis epidemic. Int $J$ Tuberc Lung Dis. 2017;21(8):852-861. doi:10.5588/ ijtld. 16.0584

10. Lee LY, Tung HH, Chen SC, Fu CH. Perceived stigma and depression in initially diagnosed pulmonary tuberculosis patients. J Clin Nurs. 2017;26(23-24):4813-4821. doi:10.1111/jocn.13837 
11. Molla A, Mekuriaw B, Kerebih H. Depression and associated factors among patients with tuberculosis in Ethiopia: a cross-sectional study. Neuropsychiatr Dis Treat. 2019;15:1887-1893. doi:10.2147/NDT.S208361

12. Ozturk F, Hisar F. Stigmatisation of tuberculosis patients. Int J Community Med Public Heal. 2014;1(1):37. doi:10.5455/23946040.ijcmph20141108

13. Duko B, Gebeyehu A, Ayano G. Prevalence and correlates of depression and anxiety among patients with tuberculosis at WolaitaSodo University Hospital and Sodo Health Center, WolaitaSodo, South Ethiopia, Cross sectional study. BMC Psychiatry. 2015;15(1-7):214. doi:10.1186/s12888-015-0598-3

14. Kumar K, Kumar A, Chandra P, Kansal H. A study of prevalence of depression and anxiety in patients suffering from tuberculosis. J Fam Med Prim Care. 2016;5(1):150. doi:10.4103/2249-4863.184641

15. Adem A, Markos Tesfaye MA, Mohammed M. The prevalence and pattern of depression in patients with tuberculosis on follow-up at Jimma University Specialized Hospital and Jimma Health Center. Med Sci. 2014;3(1):955-968. doi:10.5455/medscience.2013.02.8097

16. Ambaw F, Mayston R, Hanlon C, Alem A. Burden and presentation of depression among newly diagnosed individuals with $\mathrm{TB}$ in primary care settings in Ethiopia. BMC Psychiatry. 2017;17(1):1-10. doi:10.1186/s12888-017-1231-4

17. Dasa TT, Roba AA, Weldegebreal F, et al. Prevalence and associated factors of depression among tuberculosis patients in Eastern Ethiopia. BMC Psychiatry. 2019;19(1):1-7. doi:10.1186/s12888-019-2042-6

18. Deribew A, Tesfaye M, Hailmichael Y, et al. Common mental disorders in TB/HIV co-infected patients in Ethiopia. BMC Infect Dis. 2010;10:201. doi:10.1186/1471-2334-10-201

19. Tola HH, Shojaeizadeh D, Garmaroudi G, et al. Psychological distress and its effect on tuberculosis treatment outcomes in Ethiopia. Glob Health Action. 2015;8(1):1-11. doi:10.3402/gha.v8.29019

20. Somma D, Thomas BE, Karim F, et al. Gender and socio-cultural determinants of TB-related stigma in Bangladesh, India, Malawi and Colombia. Int J Tuberc Lung Dis. 2008;12(7):856-866.

21. Abebe G, Deribew A, Apers L, et al. Knowledge, health seeking behavior and perceived stigma towards tuberculosis among tuberculosis suspects in a rural community in Southwest Ethiopia. PLoS One. 2010;5(10):1-7. doi:10.1371/journal.pone.0013339

22. Sima BT, Belachew T, Abebe F. Knowledge, attitude and perceived stigma towards tuberculosis among pastoralists; Do they differ from sedentary communities? A comparative cross-sectional study. PLoS One. 2017;12(7):1-17. doi:10.1371/journal.pone.0181032

23. Sendhilkumar M, Tripathy JP, Harries AD, Dongre AR, Deepa M. Factors associated with high stress levels in adults with diabetes mellitus attending a tertiary diabetes care center, Chennai, Tamil Nadu, India. Indian J Endocrinol Metab. 2017;21(1):56-63. doi:10.4103/2230-8210.196006

24. Reda AA, Mitchell A. Reliability and validity of the Ethiopian version of the hospital anxiety and depression scale (HADS) in HIV infected patients. PLoS One. 2011;6(1):1-6. doi:10.1371/journal. pone.0016049
25. Humeniuk R, Henry-Edwards S, Ali R, Poznyak V, Monteiro MGV. The Alcohol, Smoking and Substance Involvement Screening Test (Assist)manual for Use in Primary Care. World Health Organization; 2010.

26. Kehbila J, Ekabe CJ, Aminde LN, Noubiap JJN, Fon PN, Monekosso GL. Prevalence and correlates of depressive symptoms in adult patients with pulmonary tuberculosis in the Southwest Region of Cameroon. Infect Dis Poverty. 2016;5(1):1-8. doi:10.1186/s40249-016-0145-6

27. Gul E, Sajjad A, Masood Jalal MH. Frequency of depression in patients suffering from pulmonary tuberculosis. Pak J Chest Med. 2017;23(1):3-7.

28. ALINAITWE R. Prevalence and Factors Associated with Depressive Illness in Patients with Tuberculosis in Mulago Hospital. Makerere university; 2018.

29. Buberwa G. Prevalence of Depression Among Tuberculosis Patients Attending Clinics in Temeke Municipal, Dar Es Salaam, Tanzania. Muhimbili University of Health and Allied sciences; 2013.

30. Masumoto S, Yamamoto T, Ohkado A, Yoshimatsu S, Querri AG, Kamiya Y. Prevalence and associated factors of depressive state among pulmonary tuberculosis patients in Manila, the Philippines. Int $J$ Tuberc Lung Dis. 2014;18(2):174-179. doi:10.5588/ ijtld. 13.0335

31. Wang X, Li X, Zhang Q, Zhang J, Chen H, Zhang J. A survey of anxiety and depressive symptoms in pulmonary tuberculosis patients with and without tracheobronchial tuberculosis. Front Psychiatry. 2018;9:308.

32. Dargie B, Tesfaye G, Worku A. Prevalence and associated factors of undernutrition among adult tuberculosis patients in some selected public health facilities of Addis Ababa, Ethiopia: a cross- sectional study. BMC Nutr. 2016;2(7):1-9. doi:10.1186/ s40795-016-0046-x

33. Sadock BJ, Sadock VA, Ruiz P. Kaplan and Sadock's Synopsis of Psychiatry: Behavioral Sciences/Clinical Psychiatry. 11th ed. Philadelphia: Lippincott Williams and Wilkins and Wolter Kluwer Health; 2014

34. Yimam K, Kebede Y, Azale T. Prevalence of common mental disorders and associated factors among adults in Kombolcha Town, Northeast Ethiopia. J Depress Anxiety. 2014;1:1-6.

35. Vancampfort D, Koyanagi A, Ward PB, et al. Perceived stress and its relationship with chronic medical conditions and multimorbidity among 229, 293 community-dwelling adults in 44 low- and middle-income countries. Am J Epidemiol. 2017;186(8):979-989. doi:10.1093/aje/kwx159

36. Kibrisli E, Bez Y, Yilmaz A, et al. High social anxiety and poor quality of life in patients with pulmonary tuberculosis. Medicine. 2015;94(3):e413. doi:10.1097/MD.0000000000000413
Neuropsychiatric Disease and Treatment

\section{Publish your work in this journal}

Neuropsychiatric Disease and Treatment is an international, peerreviewed journal of clinical therapeutics and pharmacology focusing on concise rapid reporting of clinical or pre-clinical studies on a range of neuropsychiatric and neurological disorders. This journal is indexed on PubMed Central, the 'PsycINFO' database and CAS, and is the official journal of The International Neuropsychiatric Association (INA). The manuscript management system is completely online and includes a very quick and fair peer-review system, which is all easy to use. Visit http://www.dovepress.com/testimonials.php to read real quotes from published authors. 